\title{
A Relevância do Conhecimento Histórico das Ginásticas na Formação e Atuação do Profissional de Educação Física
}

\author{
Juliana Frâncica Figueiredo ${ }^{1}$ \\ Dagmar Aparecida Cynthia França Hunger ${ }^{2}$ \\ ${ }^{1,2}$ Núcleo de Estudos e Pesquisas em Formação Profissional no Campo da Educação \\ Física (NEPEF), UNESP Rio Claro, SP, Brasil \\ ${ }^{2}$ Faculdade de Ciências. UNESP - Univ Estadual Paulista, Campus de Bauru, \\ Departamento de Educação Física, Campus de Bauru, SP, Brasil
}

\begin{abstract}
Resumo: As Ginásticas, em sua extensa contextualização histórica, fizeram parte da fundamentação da área hoje conhecida como Educação Física. Aprofundar os conhecimentos históricos provenientes das Ginásticas durante a formação acadêmica é de suma importância para a atuação profissional em Educação Física, a medida que esses conhecimentos podem servir de ferramenta para a configuração atual das Ginásticas. Destarte, esse estudo apresenta uma revisão de literatura que pretende primar pela importância do conhecimento histórico das Ginásticas durante a formação acadêmica, perspectivando que se busque refletir o formato atual das mesmas a partir de um conhecimento historicamente construído, pois é a partir da preservação de referido conhecimento que serão legitimados novos caminhos ao desenvolvimento das Ginásticas.
\end{abstract}

Palavras-chave: Ginásticas. História.Conhecimento.

\section{The Relevance of Historical Knowledge of Gymnastics in the Formation and Operation of Physical Education Professional}

\begin{abstract}
The Gymnastics, in its extensive historical background, were part of the reasoning in the area now known as Physical Education. Deepening the knowledge from the historical Gymnastics during his education is extremely important for professional performance in Physical Education, as this knowledge can serve as a tool for the current configuration of the Gymnastics. Thus, this study presents a review of the literature that you want the frontline of the importance of historical knowledge Gymnastics during his education, is looking ahead to fetch reflect the current format of the same from an informed historically built as it is from the preservation of the knowledge that will be legitimized new avenues for the development of Gymnastics.
\end{abstract}

Key Words: Gymnastics. History.Knowledge.

\section{Introdução}

"Porque temos que estudar história em um curso de graduação em Educação Física?" (MELO, 1997, p.56). O autor, há uma década, já explicitava em seu texto os motivos de se estudar história na formação profissional em Educação Física e, ele ainda questiona qual seria a contribuição de estudos de história para a formação de futuros professores. Partindo dessas questões fundamentais, argumenta sobre a seriedade com que se deve estudar história durante 0 período da graduação ressaltando 0 valor e a importância desse campo de estudos.

Quando Melo (1997, p.58) destaca a referida importância da história para a formação acadêmica em Educação Física afirma que a mesma "tem um caminho para contribuir na compreensão da sociedade que se diferencia (e deve se diferenciar), embora não se negue a dialogar, de outros campos do conhecimento". Ainda garante que "entre as ciências sociais, a história tem se apresentado entre as que mais tem procurado o diálogo com outras áreas do conhecimento".

Nessa linha de pensamento, o texto que segue pretende encaminhar os questionamentos de Melo (1997) para a área específica das Ginásticas, ou seja, caracterizar a relevância do estudo histórico das Ginásticas durante a formação acadêmica em Educação Física.

A história, bem como as pesquisas de cunho histórico, devem receber durante os cursos de formação profissional um olhar mais criterioso e diferenciado, pois é a partir daquilo que se conhece sobre 0 passado que se pode tentar modificar o presente, bem como objetivar o futuro. Assim, conhecer o que foram as Ginásticas tanto em outros momentos históricos, quanto em outras nações poderá trazer benefícios significativos ao que estão sendo as Ginásticas atualmente. Haja vista que o compartilhar de idéias entre diferentes épocas e civilizações pode se traduzir em rico 
material de estudo. E, Goellner (2003) enfatiza que recorrer, portanto, à pesquisa histórica significa recorrer a memórias entendendo-as como possibilidades de compreender que ali estão inscritas sensações, ideologias, valores, mensagens e preconceitos que permitem conhecer parte do tempo onde foram produzidos e que podem nos auxiliar a compreender um tempo que pouco conhecemos.

$\mathrm{Na}$ linha de pensamento da autora significa perceber que, ainda que as Ginásticas tenham altamente se configurado na vida moderna, elas não são invenções do presente. Resultam de conceitos e práticas há muito estruturadas no pensamento ocidental cujos significados foram e são alterados não só no tempo mas também no local onde aconteceram e acontecem.

A história, não apenas no campo da Educação Física, mas em outros campos educacionais, apresentou extremas transformações quanto à sua metodologia e objetos de estudo. Buscando sistematizar as transformações na história no último século, Burke (1992) destaca que a mesma expandiu como ofício e forma de conhecimento principalmente porque, superou a base clássica da história política incorporando aos estudos históricos a totalidade da atividade humana em suas múltiplas possibilidades temáticas e metodológicas; passou a compartilhar conhecimentos com as demais ciências sociais que estudam o homem; buscando um estatuto científico, projetou uma análise das estruturas e movimentos sociais de caráter mais geral em detrimento da narrativa acontecimental; substitui a preocupação com a trajetória dos heróis e dos personagens - vistos como sujeitos históricos pela idéia de 'história vista de baixo' trazendo a tona múltiplas experiências, olhares e vozes de uma dada temporalidade; ampliou a idéia de fonte documental em função da diversificação dos objetos e dos problemas pertinentes à investigação histórica; redimensionou a idéia de verdade objetividade.

Diante destas transformações ocorridas no campo da história, também as Ginásticas, seja com caráter de atividades físicas ou de modalidades esportivas, apresentaram nuances diferenciadas no decorrer de seu processo configuracional. Com isso, partir-se-á de uma revisão de literatura apresentando o significado da história e do conhecimento histórico das Ginásticas, refletindo significativamente sobre sua acuidade na formação.

\section{O Significado da História na Formação}

Inicialmente partir-se-á da introdução dos conceitos gerais de história que serviram de base para a fundamentação deste texto que, trata-se de um olhar relativamente contemporâneo de se fazer história. Esta forma surgiu por volta de 1920 e tem como seus principais idealizadores, Bloch e Febvre, que segundo Vainfas (1997, p.130):

... Combatiam uma história que, pretendendo-se
científica, tomava como critério de cientificidade
a verdade dos fatos, à qual se poderia chegar
mediante a análise de documentos verdadeiros
e autênticos (ficando os 'mentirosos' e 'falsos' à
margem da pesquisa histórica) (...) Combatiam,
enfim, uma história que se furtava ao diálogo
com as demais ciências humanas, a
antropologia, a psicologia, a lingüística, a
geografia, a economia e, sobretudo, a
sociologia, rainha das disciplinas humanísticas
na França desde a obra de Durkheim.

A história, que atravessa 0 século $X X$ perfazendo grupos contrários às diferentes formas de compreensão, interpretação e aplicação da mesma é visualizada por Chartier (1994, p.98) como uma disciplina que:

se afastou de uma simples cartografia das particularidades ou de um simples inventário, jamais concluído, aliás, de casos ou fatos singulares. A história pôde assim retomar a ambição que havia fundado no início deste século a ciência social, especialmente na sua versão sociológica e durkheimiana: identificar estruturas e regularidades, e portanto, formular relações gerais.

Segundo o autor, nas últimas duas décadas a história modificou-se completamente quanto à maneira de tratar seu(s) objeto(s) de estudo(s), se baseando agora em "modelos interacionistas e etnometodológicos". Chartier (1994, p.98) ainda alega que não são mais "as estruturas e os mecanismos que regulam, fora de qualquer controle subjetivo, as relações sociais, e sim as racionalidades e as estratégias acionadas pelas comunidades, as parentelas, as famílias, os indivíduos".

A história passou de uma história de heróis e grandes feitos baseados nas "narrativas antigas" para uma "nova história" em que "se instalava entidades anônimas e abstratas" (CHARTIER, 1994, p.98). Hoje, se pondera a possibilidade de conceitos mais amplos e flexíveis de história, como a história social e a história cultural que 0 autor retrata em seu texto, desmistificando quase que completamente um conceito de história tendo como objeto de estudo apenas e exclusivamente o que 'passou', o que 'morreu'.

Conforme explicitado acima, a fundamentação conceitual referente à 'nova' história permite pensar a maneira como a história das Ginásticas vem sendo estudada e disseminada em meio acadêmico. $O$ valor desse conhecimento histórico é demasiado importante na medida em que, 
partindo destes conhecimentos é que se projetaram as mudanças na área das Ginásticas. Foi também a partir das transformações das Ginásticas no século passado que se configurou a Educação Física no mundo.

Nessa perspectiva de se observar a história, é possível perceber que o conhecimento histórico influencia diretamente o presente, sendo assim também um estudo contemporâneo, permitindo aqui apoiar-se em Bloch (1965, p.13) que indicava que a história não tem prioritariamente como objeto de estudo tão somente o passado, mas também o uso que se faz deste no presente. $O$ autor assim escreve que não se deve "definir a história como simples ciência do passado, mas como o resultado de um vai e vem constante do historiador do presente ao passado e do passado ao presente".

Marrou (1969, p.03) apoiando a nãolinearidade e fixação da história em fatos estáticos coloca que:

O conhecimento histórico, aspecto particular do conhecimento do homem, é essencialmente movediço e sempre provisório. Nossas idéias a respeito do homem, do mundo e da vida não cessam de transformar-se: não há assunto histórico que não seja necessário retomar periodicamente para reenquadrá-lo numa perspectiva exata, por haver-se modificado, entrementes, a visão de conjunto.

A configuração histórica das Ginásticas se encaixa com plenitude nos escritos do autor, pois as próprias formas que elas apresentaram com 0 passar dos anos foram provisórias, modificandose de acordo com as novas necessidades dos homens de vivenciar o corpo em termos de práticas corporais. $\mathrm{E}$, com isso há a necessidade latente de retomar o 'assunto histórico' Ginásticas sempre que possível para 'reenquadrá-lo' numa perspectiva atual.

Para tanto, é necessário reconhecer que este conhecimento do passado - conhecimento histórico - no instante em que se deseja apreendê-lo, não se deve perder a capacidade de observar a realidade do passado, mesmo se encontrando em um outro momento histórico. A esta capacidade Marrou (1969, p.40) chama de sentido histórico. Considerando que o

que nos separa do objeto do passado não é um espaço vazio: através do tempo intermediário os acontecimentos estudados - quer se trate de ações, de pensamento, de sentimentos produziram seus frutos, arrastaram consigo conseqüências, desenvolveram as virtualidades e não podemos separar o conhecimento que deles temos do destas seqüelas.

Assim, o espaço que separa, por exemplo, a introdução dos Métodos Ginásticos no Brasil, dos estudos sobre movimentos altamente arriscados que realizam os ginastas brasileiros atualmente, não passou em branco. Ao menos não deveria! Esse espaço deve ser freqüentemente relembrado, avaliado, questionado e, principalmente, apresentado à futuros profissionais para que estes entendam as diferenças, as similaridades, as particularidades de cada momento histórico e, o que cada momento histórico ofereceu de conhecimento e contribuição às Ginásticas.

Contudo, Melo (1997, p.56) aponta com pesar que o ensino de história nos cursos de Educação Física

ainda tem se resumido a apresentação dos chamados 'conteúdos clássicos'. Apresenta-se uma série de nomes e fatos eleitos como relevantes, enquadrados no interior de períodos consagrados tradicionalmente e importados da História Geral (Grécia Antiga, Roma, Idade Média etc.), a partir de uma ausente, confusa ou não consciente compreensão historiográfica.

Assim, tem-se a informação, conhecem-se alguns fatos históricos relevantes da Educação Física, ou das Ginásticas especificamente, porém não se critica coerentemente este conhecimento histórico de maneira que este possa ser estimado e, Melo (1997, p.56) destaca que "esta situação se propaga por gerações, sem que a história venha a ser devidamente valorizada".

Schaff (1991, p.73), aprofundando-se na temática do conhecimento histórico, entende que no processo deste há uma "interação específica do sujeito que conhece $e$ do objeto do conhecimento, tendo como resultado os produtos mentais a que chamamos o conhecimento".

O conhecimento é um processo infinito, mas um processo acumulando as verdades parciais que a humanidade estabelece nas diversas fases do seu desenvolvimento histórico: alargando, limitando, superando estas verdades parciais, o conhecimento baseia-se sempre nelas e tomaas como ponto de partida para um novo desenvolvimento. (ㄷHAFF, 1991, p.97)

Esse 'conhecimento histórico' tratado aqui, envolvendo as Ginásticas, não será nada mais que redações sobre 0 passado se não for reelaborado, testado e significativamente aproveitado no espaço de formação profissional para futuras mudanças e melhorias, tanto na vertente teórica quanto na vertente prática, já que ambas mudam suas configurações a cada dia. Para tanto, o valor dado à história de fatos e acontecimentos sejam muito antigos, ou mais contemporâneos deve ser continuamente reconhecido e estudado nos cursos de Educação Física. 
Melo (1997, p.57) que discute também em seu texto a inclusão de cadeiras (termo mais utilizado para disciplinas no início da criação dos cursos de Educação Física no Brasil), afirma que era diferenciado o status destinado a cadeiras teóricas e práticas, bem como cadeiras da área médica e não médica. Assim, a cadeira de história "gozava de um prestígio intermediário, já que embora fosse teórica, era não-médica" e, o autor complementa colocando que este prestígio acabava por ser reduzido, pois a cadeira acabava "por ser considerada de uma utilidade prática menor" (grifo do autor).

A questão da "preocupação prática" na área da Educação Física, alertada por Melo (1997, p.57), possivelmente relegou à história, nos currículos dos cursos de formação profissional, um espaço de segundo plano. Ele destaca que:

Isto é, se acharmos que a formação e a preparação profissional em nível superior tem o único intuito de dar fórmulas fechadas, soluções lineares, modelos de atuação a serem seguidos inquestionavelmente, a História tem realmente uma duvidável validade e relevância. Dentro desta perspectiva, suas funções se restringiriam à mera informação despretensiosa, um objeto de curiosidade ou a distorcidamente justificar o presente.

Goellner (2005, p.79) afirma que no estudo de história, e a autora trata especificamente de estudos sobre esporte, não é satisfatório apenas "evitar o esquecimento". E, continua destacando que "não basta resgatar e preservar a memória (ainda que essa seja tarefa necessária), mas fundamentalmente, há que lhe conferir significações, contextualizá-la no seu tempo, analisá-la, permitir que dela originem-se diferentes interpretações". E, aqui cabe questionar se os cursos de formação acadêmica em Educação Física estão resgatando, preservando, conferindo significação e originando diferentes interpretações das manifestações corporais historicamente concebidas, como por exemplo, as Ginásticas.

$\mathrm{Na}$ ampliação de pesquisas na área da Educação Física, é possível observar que de certa forma as Ginásticas são e, talvez continuem sendo, expostas em estudos diversos com os mais variados objetivos, uma vez que perfazem o processo de constituição histórica da Educação Física mundial. Contudo trata-se de uma descrição histórica e muito pouco de uma contextualização e discussão que busque no conhecimento histórico o que foi e o que vem a ser as Ginásticas. Construir uma representação de um determinado passado humano é aceitar sua complexidade, tudo que the pertenceu, tentando apreender o máximo possível sobre ele.
Para apreender este passado "é preciso encerrálo estreitamente numa rede de perguntas sem escapatória, obrigá-lo a confessar-se" (MARROU, 1969, p.53).

Para tanto, Melo (1997) aponta a necessidade de melhorias na história que se ensina nos cursos de graduação, uma vez que assim é possível fazer com que esse passado 'se confesse' a partir de uma 'rede de perguntas', e permita novas mudanças às práticas corporais, especificamente as Ginásticas. Com base em Melo (1997), o valor do conhecimento histórico que as Ginásticas geram deve ser instituído nos cursos de graduação como fator de referência para a conservação da memória de manifestações corporais historicamente construídas.

Observando a maneira plural e interdisciplinar pela qual a história se aplica a todas as ciências, para as diversas áreas do saber, dentro de diferentes campos de estudo, a preservação de seu conhecimento é de suma importância. Destarte, é preciso que se faça a reconstrução dos conhecimentos históricos da humanidade para resguardar os fatos que refletem no presente e assim também o farão no futuro, não sendo menos importante para o campo da Educação Física, designadamente na área das Ginásticas. Nesse sentido, seguem momentos importantes da história das Ginásticas, que notadamente, porém não somente, deveriam ser abordados nos cursos de formação acadêmica em Educação Física.

\section{Contextualização Histórica das Ginásticas}

Ao analisar as Ginásticas no tempo, notou-se que seu passado foi se modificando de acordo com as necessidades de cada momento histórico, e de cada nação. Segundo Fiorin $(2002$, p.17) "a Ginástica, sendo entendida como sinônimo de atividades físicas em geral vai ganhando roupagens diferentes de acordo com as épocas, culturas e interesses distintos" (grifo da autora). Cabe colocar que, como a história num contexto geral, também a história das Ginásticas passou por uma mutação, com explicações às suas mudanças (LE GOFF, 1992). Ao estudar a história das Ginásticas, deve-se estar convicto do objeto de estudo, já que a historiografia a cerca deste conteúdo remonta de muitos anos aplicando-se a diversas formas de movimentações corporais, que foram melhor 'racionadas' há cerca de meio século.

As Ginásticas - com interpretação própria do termo - surgem na Antigüidade, em que estudiosos gregos criaram o termo Gymnus: nu (tratando-se da prática de atividades com o corpo desnudo). Na época foram também criadas as 
primeiras sistematizações de atividades físicas, o que para Publio (2002) ressalta a importância da Antigüidade Grega no aspecto histórico das Ginásticas.

Marrou (1969, p.185) coloca com propriedade o auge das Ginásticas na Antigüidade grega:

(...) a ginástica permanece o elemento, senão preponderante, pelo menos característico da formação do jovem grego, o gosto pelos desportos atléticos e pela sua prática constitui, como na época arcaica, um dos traços dominantes da vida grega, (...).

Neste período - Greco-Romano - existiam diferentes formas de aplicação das Ginásticas. Em Atenas tinha-se o ideal do culto ao corpo, sendo a prática de exercícios físicos altamente valorizada como educação corporal (SOUZA, 1997). Enquanto os espartanos e romanos praticavam exercícios físicos para a preparação de soldados para guerrear. Souza (1997) descreve que em Roma, as Ginásticas também serviam de preparo para as atividades esportivas do período - luta de gladiadores e cavaleiros.

Com o lluminismo, filósofos e pedagogos relegaram grande importância à prática das Ginásticas - como um bem para a formação integral do homem seguida dos médicos que, acreditavam na atividade física como benefício à saúde, auxiliando na ascensão das Ginásticas pelo Ocidente.

Em meados do século XVIII, surgem os primeiros idealizadores, ou 'sistematizadores' das Ginásticas e, a partir deles os Métodos Ginásticos. Estes idealizadores formularam seus Métodos "(...) com princípios da cultura da Grécia antiga, que enaltecia a saúde, a força e a beleza (...)" (BREGOLATO, 2002, p.75). A autora discorre que dentre os Métodos idealizados no século XVIII, os Métodos Alemão, Sueco e Francês, foram os que obtiveram maior penetração na Europa e nos demais continentes.

Os Métodos Ginásticos tiveram desenvolvimentos simultâneos, favorecendo a troca de informações entre os mesmos. A ascensão destes Métodos se difundiu por toda a Europa, dotada de um sentimento nacionalista como forma de causar melhorias físicas aos jovens que enfrentariam as guerras da época, bem como melhorias étnico-raciais à nação (MENEGHETTI, 2003).

Para Bregolato (2002, p.76), "as atividades físicas eram de utilidade para o indivíduo, que se reverteria em utilidade para a nação". Estas prerrogativas políticas militares dos Métodos Ginásticos permaneceram no século XX, acompanhando o desenvolvimento da Educação
Física pelo mundo. Ayoub (2003, p.107) destaca "que durante todo o séc. XIX e início do séc. XX, a ginástica (que compreendia exercícios militares, jogos, dança, esgrima, equitação e canto) era o conteúdo de ensino da Educação Física escolar".

É inegável, portanto, a contribuição das Ginásticas para o desenvolvimento histórico da Educação Física escolar. Foi utilizando a nomenclatura Ginástica que as atividades relacionadas ao corpo e ao movimento penetraram em âmbito educacional compondo os currículos obrigatórios. Assim, pensar nas Ginásticas leva à necessidade de refletir a respeito de quem as ministrava e de que maneira acontecia a formação destas pessoas.

\section{A Formação do Educador Ginástico: da Antigüidade à Modernidade}

Já na Antigüidade nota-se a existência do 'educador de Ginástica' ou 'educador físico', o 'paidotribé', que era além de um monitor de Ginásticas, tratava-se de um educador:

(...) que à sua competência desportiva, devia reunir profundo conhecimento das leis da higiene e de tudo o que a ciência médica grega elaborara quanto a observações e prescrições relativas ao desenvolvimento do corpo, aos efeitos dos diversos exercícios, aos regimes convenientes aos diversos temperamentos. (MARROU, 1969, p.196)

Segundo o autor, não era apenas pelo exemplo e pela prática que se ensinavam as Ginásticas nesse período, havia a apropriação de um conhecimento superior, ou seja, aqueles que ensinavam Ginásticas deveriam ter uma abrangente sabedoria filosófica sobre corpo e mente. Marrou (1969, p.197) relata que para os gregos "o gosto pelo pensamento claro exigia tomada de consciência, uma análise minuciosa dos diferentes movimentos postos em jogo pelos exercícios".

Na Idade Contemporânea, com a ascensão dos Métodos Ginásticos e sua inserção na escola houve a necessidade de se criar escolas que formassem esses educadores. Surgem então, por todo o continente europeu, escolas e institutos voltados à formação de professores de Ginástica.

O dinamarquês Franz Netchegal, que influenciou as Ginásticas em seus aspectos educativos, "em 1808 inaugura um instituto civil de Ginástica para a formação de professores" (OLIVEIRA, 1985, p.7). Em 1852, na França, Amoros - idealizador do método Francês - funda "a Escola Normal de Ginástica de Joinville-lePont, próxima de Paris, onde oferecia cursos de Ginástica para oficiais" (BREGOLATO, 2002, p.89) 
A formação do educador contemporâneo era tão ampliada quanto à dos paidotribés gregos, dado a gama de práticas que as Ginásticas compreendiam desde a Antigüidade. Para elucidar a questão do educador ginástico contemporâneo, Soares (2000, p.55-56), adota as obras dos franceses Amoros e Demeny - biólogo que realizou estudos sobre a formação do educador ginástico.

Amoros, segundo a autora, acreditava que para se ensinar Ginásticas, era de grande importância ter "formação no campo da Filosofia" e refletir sobre a "educação dos sentidos" realizando um "refinamento do espírito", em que os "saberes sensíveis" seriam o alicerce da formação. A partir destes, é que se poderia passar aos "saberes científicos" como, "Anatomia, Fisiologia, Mecânica". O educador de Ginásticas ainda deveria comportar conhecimentos sobre "tecnologia", apreendendo "cálculo e geometria" para a "construção, reforma e criação de máquinas e instrumentos para as aulas". Toda esta gama de conhecimentos serviria para 0 educador desenvolver nos alunos as faculdades físicas e morais.

Já para Demeny, a autora destaca que, "quem ensinava Ginástica deveria reunir os conhecimentos do sábio, bem como aqueles do prático para, então, adaptá-los ao conhecimento do homem". Demeny denominava o educador ginástico de 'engenheiro biologista', o que reforça muito a valorização tecno-científica e biologicista da época. "E a Ginástica compunha este mosaico de certezas, onde apenas as ações úteis e passíveis de comprovações experimentais tinham lugar".

Deste modo, é possível observar que as Ginásticas passam de uma atividade meramente prática, para uma atividade que requer formação técnica, teórica e intelectual em que, aquele que as ministrava deveria ter o mínimo de conhecimento para ensiná-las. No Brasil a maneira como se dá o desenvolvimento da formação de profissionais capacitados para o trabalho com as Ginásticas não é muito diferente do que acontece no restante do mundo. E assim como na maioria dos países, também no Brasil, são as Ginásticas que vão figurar o que na seqüência é denominado Educação Física, como será relatado a seguir.

\section{A Formação para o Trabalho com as Ginásticas no Brasil}

A necessidade de se formar professores que trabalhassem com atividade física - educação corporal - surge com a Reforma Couto Ferraz, em 1851, e, três anos depois, com sua regulamentação através da Lei ㄲo. 630, que confere a obrigatoriedade das Ginásticas nas escolas (DARIDO, 2003; $\underline{\text { PIRES }}$, 2006).

Marinho (1943) relata que, as iniciativas de formação de professores para ministrarem Ginásticas que avançaram no Brasil, como a criação da Escola de Educação Física da Força Policial em 1909, restringiram-se à capacitação militar.

Melo (1997), aponta que em 1922, é fundado o Centro Militar de Educação Física no Rio de Janeiro, que daria origem futuramente à Escola de Educação Física do Exército (EsEFEx). A EsEFEx foi criada com a intenção de formar instrutores, monitores, mestre d'arma, monitores de esgrima e médicos especializados para o exército. Seus cursos eram oferecidos para militares e, eventualmente, civis podiam realizar o curso de monitor.

Muitas propostas quanto à criação de cursos surgiram durante as décadas de 20 e 30 , no entanto Pires (2006, p.182) afirma que:

(...) o primeiro programa sistematizado de Educação Física no Brasil, foi o curso da Escola de Educação Física do Estado de São Paulo, criado em 1931, mas que só começou a funcionar em 1934. Este curso tinha como propósito a formação de dois profissionais distintos, quais sejam: Instrutor de Ginástica e o Professor de Educação Física.

$O$ autor descreve que os saberes do instrutor de ginástica deveriam abranger "o estudo da vida humana em seu aspecto celular, anatômico, funcional, mecânico, preventivo, estudo dos exercícios físicos da infância a idade madura, estudos dos exercícios motores, lúdicos e agonísticos" (p.182).

Em 1939, com a realização de revisão na proposta de formação profissional do curso citado, passam agora a ser cinco formações quais sejam: instrutores de ginástica (professores primários), professor de Educação Física, médico especializado em Educação Física, técnico em massagem, técnico desportista. (PIRES, 2006)

É notório que as Ginásticas perfazem a formação dos profissionais e dos cursos superiores, sendo inegável sua contribuição ao desenvolvimento do que hoje se concebe como Educação Física seja na escola, seja na universidade.

No âmbito da educação básica, antes mesmo que houvesse profissionais proferindo o ensino das Ginásticas, estas passam a fazer parte dos conteúdos a serem desenvolvidos na escola. Dessa maneira, por meio das mais diversas indicações de profissionais como médicos e 
pedagogos, alegadas por diferentes objetivos que vão desde a saúde da nação à retidão militar, as Ginásticas passam para o espaço da educação formal, sendo incluídas agora nos currículos educacionais.

\section{A inclusão das Ginásticas na Escola e nas Escolas Brasileiras}

As Ginásticas com caráter pedagógico foram idealizadas a princípio pelo alemão Guths Muths em 1793, "mas suas idéias ficaram em segundo plano quando Napoleão derrotou os alemães em 1805" (BREGOLATO, 2002, p. 84). Este fato despertou um forte sentimento nacionalista enaltecendo o Método Alemão, onde seu idealizador Friedrich Ludwing Jahn, se apóia em características sócio-militares para desenvolvê-lo.

Adolph Spiess - nome importante da Ginástica alemã - "preocupa-se com a Ginástica nas escolas" (OLIVEIRA, 1985, p.07). Spiess propõe que um período do dia seja dedicado ao exercício físico, porém, sua sistematização de Ginásticas é mecânica e funcional (MENEGHETTI, 2003), e mesmo assim é implantada nas escolas alemãs por volta de 1820.

Foi a Dinamarca, em 1801, o primeiro país a incluir as Ginásticas nas escolas, influenciada pelas idéias de Franz Netchegal, que em 1928, consegue que o ensino das Ginásticas na escola seja obrigatório (OLIVEIRA, 1985). O Método Dinamarquês não teve a mesma força de aceitação como o Alemão, Francês e Sueco, justamente pelo seu caráter pedagógico em contraposição ao militar.

Outro fato importante para as Ginásticas se retrata a partir do Método Francês na segunda metade do século XIX, em que Bregolato (2002, p.89) coloca:

Após a derrota na guerra franco-prussiana de 1870-71, as autoridades atribuíram à degeneração física e moral a culpa pela derrota nacional. Com isso, leis foram criadas no sentido de tornar obrigatória a Ginástica no currículo escolar, com o fim de melhorar a condição física e moral do povo.

Com isso, o Método idealizado por Amoros é implantado em todas as escolas da França, sendo sua prática obrigatória para os escolares de ambos os sexos. Seguindo a mesma orientação de diversos países, os quais passam a ter a prática de Ginásticas como atividade obrigatória em seus currículos escolares, é que o Brasil vai incluir as Ginásticas nas escolas.

Em meados do século XVIII, as Ginásticas foram inseridas no Brasil, visando a preparação física dos soldados da Corte e, o primeiro sistema de Ginásticas a ser implantado no país oficialmente foi o alemão, na primeira metade do século XIX (MARINHO, 1943).

Dentro dos momentos históricos das Ginásticas no país, Meneghetti (2003, p.16) registra que a introdução do Método Alemão no Brasil deve-se ao significativo número de imigrantes refugiados da guerra que se instalaram no país e que tinham como hábito essa prática. Segundo a autora, "esse contingente populacional de origem alemã cria inúmeras sociedades de Ginástica com as características básicas traçadas por Jahn, Guts Muths e Spiess".

O Método Alemão, por volta de 1860, é consagrado como o método oficial do exército brasileiro e, em 1870 o Ministro do Império determina a tradução e publicação do 'Novo Guia para o ensino de Ginástica nas Escolas Públicas da Prússia'.

Como já citado anteriormente, as Ginásticas chegam às escolas brasileiras por intermédio da reforma Couto Ferraz, tendo como aporte o Método Alemão. Porém a consolidação das Ginásticas na escola se dá a partir de Rui Barbosa, com a reforma de 1882, quando institui o Método Sueco na educação.

Em 1882, Rui Barbosa deu seu parecer sobre o Projeto 224 - Reforma Leôncio de Carvalho, Decreto n. 7.247, de 19 de abril de 1879, da Instrução Pública -, no qual defendeu a inclusão da ginástica nas escolas e a equiparação dos professores de ginástica aos das outras disciplinas. Nesse parecer, ele destacou e explicitou sua idéia sobre a importância de se ter um corpo saudável para sustentar a atividade intelectual. (BRASIL, 1997, p.19)

Com a reforma, "houve recomendação para que a Ginástica fosse obrigatória, para ambos os sexos, e que fosse oferecida para as Escolas Normais" (DARIDO; SANCHEZ NETO, 2005, p.2). Contudo, os autores, bem como Betti (1991) colocam que até os primeiros anos da década de 30 , as leis propostas pela reforma, foram aderidas apenas pelas escolas do Rio de Janeiro, como município da corte imperial e capital da República, e as escolas militares.

Em 1920 passa a ganhar espaço na escola o Método Francês, que a partir de 1930 passa a ser usado como meio para a política Getulista, onde se pretendia um homem forte para a produção da indústria brasileira. É também na década de 20 que "vários estados da federação começam a realizar suas reformas educacionais e incluem a Educação Física, com o nome mais freqüente de Ginástica" (DARIDO; SANCHEZ NETO, 2005, p.2). 
O Método Francês passa a ser obrigatório nas escolas brasileiras até por volta de 1960, quando o esporte começa a ser inserido em âmbito escolar, reforçado pelas vitórias da Seleção Brasileira de Futebol em duas Copas do Mundo (DARIDO; SANCHEZ NETO, 2005). Também a nomenclatura mais utilizada agora é a de Educação Física e as Ginásticas aos poucos vão deixando de ser 'a' Educação Física para se tornar um conteúdo a ser ministrado nas aulas na escola.

Dessa maneira, a partir de um amplo desenvolvimento tecnológico e de mudanças epistemológicas no campo Educação Física, as Ginásticas passam a ser uma sub-área da Educação Física, sendo divididas em campos distintos de atuação que são apresentados na seqüência.

\section{Campos de Atuação da Ginástica}

Souza (1997) apresenta uma divisão para demarcar o amplo universo das Ginásticas e melhor compreendê-lo. Nele são apresentados cinco grandes grupos que englobam os principais campos de atuação das Ginásticas. Dentro destes campos de atuação a autora também exemplifica as modalidades que os constituem.

I) Ginásticas de Condicionamento Físico - fazem parte todas as Ginásticas que objetivam adquirir ou manter a condição física do indivíduo. Dentro deste campo tem-se: Ginástica Localizada, Musculação, Step, Ritmos, etc. - são exercícios de repetição com ou sem peso adicional, com ou sem aparelhos, atuando sobre um ou mais músculos, aumentando ou mantendo a capacidade aeróbica e/ ou anaeróbica do indivíduo.

II) Ginásticas de Competição - são todas aquelas que possuem códigos e regras, onde o objetivo a ser alcançado é a vitória. As Ginásticas Competitivas são:

- Ginástica Artística - com utilização de aparelhos, seis no masculino e quatro no feminino, e para a contagem das notas são considerados: dificuldade, combinação, originalidade e execução dos elementos;

- Ginástica Rítmica - é uma Ginástica exclusivamente feminina, envolvendo movimentos de expressão corporal com ênfase em danças de variados tipos e dificuldades, combinadas com a manipulação de equipamentos pequenos, como cordas, arcos, massas, fitas e bolas;

- Ginástica Acrobática - também conhecida como Acrobacia, e apesar de muito desenvolvida no séc. VII, devido à criação do circo, ela é uma modalidade relativamente jovem, dividida em masculino, feminino e mista, podendo ser trabalhada em duplas, trios ou quartetos;
- Ginástica Aeróbica - também utilizada como forma de condicionamento, foi recentemente incluída dentro da esfera competitiva, podendo ser masculina, feminina ou mista, realizada em duplas, trios ou grupos;

- Trampolim Acrobático, Tumbling e Duplomini (mini-trampolim) - são também modalidades novas no contexto esportivo. Estes trampolins podem propulsar tão alto os atletas treinados, que estes chegam a até 30 pés durante as performances, que exigem demonstrações seqüenciais de saltos ginásticos e acrobáticos, podendo ser realizado individualmente ou em grupo, de forma sincronizada.

III) Ginásticas Fisioterápicas - utilizam o exercício físico para prevenção e tratamento de doenças, e também auxilia na recuperação de lesões. São as mais utilizadas: a RPG (Reeducação Postural Global), que se baliza na postura correta do corpo como forma de exercício; a Cinésioterapia e a Isostreching.

IV) Ginásticas de Conscientização Corporal reúnem as novas propostas de abordagem do corpo, também conhecidas como Técnicas Alternativas ou Ginásticas Suaves. Estes tipos de Ginásticas, pelo menos grande parte, tiveram sua origem na busca da solução de problemas físicos posturais. Fazem parte deste campo a Ginástica Holística, que é um trabalho corporal complementar atendendo áreas como a neurologia, ortopedia e reumatologia; a AntiGinástica; a Eutonia; o Método Feldenkrais; a Bioenergética; dentre outras.

V) Ginásticas de Demonstração - a principal característica deste tipo de Ginástica é o fato de não ser competitiva, se preocupando mais com a interação social entre os indivíduos. A Ginástica Geral é a única representante deste grupo englobando várias atividades como: as modalidades oficiais de Ginásticas competitivas, a dança em seus aspectos coreográficos expressivos e, pode ser realizada com ou sem aparelhos.

A partir do contexto histórico de desenvolvimento das Ginásticas, bem como de sua atual configuração, é possível observar que a abrangência destas ainda é vasta, comportando diferentes esferas de movimentações corporais e, segundo Souza (1997, p.25):

(...) o estabelecimento de um conceito único para ela, restringiria a compreensão deste imenso universo que a caracteriza como um dos conteúdos da Educação Física. Esta modalidade no decorrer dos tempos tem sido direcionada para objetivos diversificados, ampliando cada vez mais as possibilidades de sua utilização (...).

\section{Considerações Finais}

A partir dessa breve revisão literária, discorrendo alguns momentos históricos referentes às Ginásticas, bem como suas 
configurações atuais, buscou-se evidenciar as nuances de seu desenvolvimento em uma perspectiva histórica, tendo como objetivo primordial que estas nuances sejam conhecimentos históricos tratados durante a formação acadêmica em Educação Física.

Constatou-se que as Ginásticas foram propostas universalmente como prática corporal, nos mais diferentes momentos históricos. $E$, destacam-se aqui alguns destes momentos históricos fazendo comparações com as Ginásticas da época atual: 1) as Ginásticas para se alcançar a plenitude da beleza e da mente, na Antigüidade por intermédio do povo grego é altamente identificável entre as sociedades atuais, pois a busca do corpo belo por meio das Ginásticas de Academias e a educação do corpo para sintonizá-lo com a mente, encontrada entre as Ginásticas mais suaves, constituem um dos mercados mais procurados por clientes e profissionais atualmente; 2) as Ginásticas configuradas para se educar o corpo respeitando as regras de todo um elenco dominador, também na Antigüidade, com espartanos e romanos e nos séculos XVIII e XIX, principalmente por intermédio dos Métodos Ginásticos europeus, ocorre hoje em dia com as Ginásticas de Competição, pois se respeitam regras, técnicos, árbitros, e principalmente os financiadores dessa prática, sujeitando o corpo ao domínio ideológico do poder esportivo; 3) as Ginásticas como forma de dominação de corpos e alienação de indivíduos para uma prática higiênico-militar, propriamente dentro dos currículos escolares, em meados do século XIX e início do século XX, é identificada hoje por meio da mídia, na qual a gama de corpos 'plásticos', 'sarados' e 'siliconados', levam indivíduos leigos ao poder alienante da TV a buscarem alternativas e formas de Ginásticas para se assemelharem àqueles corpos, muitas vezes não como um bem pessoal, mas como crença de que aquela forma física é a que traz felicidade.

Evidenciou-se que as Ginásticas encontraram caminhos para se dividir atualmente trazendo consigo pontos significativos, observados talvez, apenas por intermédio de uma perspectiva histórica. Destarte, é importante que, esse conhecimento histórico seja plena e amplamente abordado no espaço da formação acadêmica profissional e, que seja apresentado de forma singular, para que se possam identificar caminhos inovadores acompanhando suas configurações.

Segundo Melo (1997, p.60),

os estudos históricos terão uma possibilidade maior de contribuir efetivamente com a Educação Física brasileira, permitindo interpretações de seus processos e caminhos no decorrer do tempo, lançando luz nas discussões contemporâneas, e, diriam alguns, até mesmo contribuindo no perspectivar do futuro. Mas isso de forma alguma significa que a História se presta a conceder lições de moral, a buscar heróis ou bandidos ou a programar o futuro e se constituir em uma verdade 'absoluta/inquestionável'. Bem possivelmente, se os professores da disciplina incorporarem esta nova forma de pensar, aliada com estratégias pedagógicas adequadas, seu ensino se tornará mais agradável e sua importância mais reconhecida no contexto dos cursos de graduação em Educação Física.

A relevância do conhecimento histórico das Ginásticas na formação acadêmica é particularmente essencial para a atuação do profissional de Educação Física, especialmente ao professor escolar. É dentro do espaço de atuação que estes profissionais podem disseminar o referido conhecimento histórico e, aprimorá-lo de acordo com as vivências atuais das Ginásticas. Partindo de um conhecimento histórico contextualizado de forma relevante, poder-se-á contribuir de maneira mais eficaz na formação crítica e consciente do cidadão, preservando bem como disseminando 0 patrimônio cultural das Ginásticas.

Acredita-se que ser um educador, seja na formação acadêmica seja na escolar, é mostrar aos alunos aquilo que vai além do presente, é voltar ao passado para se construir um futuro. É apresentar o que foi e o que pode ser e, situar esses alunos dentro dessa edificação que em muito depende deles.

A partir destas constatações, é possível citar Bloch (1965, p.42-43):

É tal a força de solidariedade das épocas que os laços de inteligibilidade entre elas se tecem verdadeiramente nos dois sentidos. A incompreensão do presente nasce fatalmente da ignorância do passado. Mas talvez não seja mais útil esforçarmo-nos por compreender o passado se nada sabemos do presente.

\section{Referências}

AYOUB, E. Ginástica Geral e Educação Física

escolar. Campinas: Unicamp, 2003.

$\mathrm{BLOCH}, \mathrm{M}$. Introdução à história. Tradução: Maria Manuel Miguel e Rui Grácio. Lisboa: Europa-América, 1965.

BRASIL. Secretaria de Educação Fundamental. Parâmetros Curriculares Nacionais: terceiro e quarto ciclos do ensino fundamental (Introdução aos Parâmetros Curriculares Nacionais). Brasília: MEC/SEF, 1998. 
BREGOLATO, R. A. Cultura corporal da cinástica. Coleção Educação Física Escolar: no princípio da totalidade e na concepção histórico-crítica, vol.2. São Paulo: ícone Editora, 2002.

BURKE, P. A escrita da história. São Paulo: Editora UNESP, 1992.

CHARTIER, R. A história hoje: dúvidas, desafios, propostas. Revista: Estudos Históricos, Rio de Janeiro, vol. 7, n. 13, 1994, p. 97-113.

DARIDO, S. C., Educação Física na Escola, 1a․ ed. Rio de Janeiro: Guanabara Koogan S.A., 2003.

; SANCHEZ NETO L. S. O Contexto da Educação Física na Escola. In: DARIDO S. C. E RANGEL I. C. A (Coord). Educação física na escola: implicações para a prática pedagógica. Rio de Janeiro: Guanabara Koogan, p.01-24, 2005.

FIORIN, C. M. A ginástica em Campinas: suas formas de expressão da década de 20 a década de 70 (Dissertação de Mestrado) Unicamp: Campinas, 2002.

GOELLNER, S. V. Bela, maternal e feminina: imagens da mulher na Revista Educação Physica. Ijuí: Editora Unijuí, 2003.

Locais da memória: história do esporte moderno. Revista Arquivos em Movimento, Rio de Janeiro, v.1, n.2, julho/dezembro, 2005, p. 7986.

LE GOFF, J. História e memória. $2^{\mathrm{a}}$ ed. Campinas: Unicamp, 1992.

MARINHO, I. P. Sistemas e métodos de educação física. São Paulo: Cia. Brasil Editora, 1943.

MARROU, H.I. História da educação na antiguidade, São Paulo: Editora Herder, 1969.

MELO, V. A. Porque devemos estudar história da educação física/esportes nos cursos de graduação? Revista Motriz, Rio Claro, v.03, n.01, Junho, 1997, p.56-61.

MENEGHETTI, L. A ginástica geral e a formação universitária na FEFISA - Faculdades Integradas. (Trabalho de Conclusão de Curso). Faculdades Integradas de Santo André, 2003.

OLIVEIRA, V. M. Educação física humanista. Rio de Janeiro: Ao Livro Técnico, 1985.

PIRES, R. G. Formação profissional em educação física no Brasil: suas histórias, seus caminhos.

Revista da Faced, Bahia, n 10, 2006, p.179-193.
PUBLIO, N. S. Evolução histórica da ginástica olímpica. 2 $2^{\mathrm{a}}$ ed, São Paulo: Phorte, 2002.

SCHAFF, A. História e verdade. $5^{\underline{a}}$ ed. São Paulo: Martins Fontes, 1991.

SOARES, C. L. Notas sobre a educação no corpo. Revista Educar. Curitiba: Editora da UFPR, n.16, p.43-60, 2000.

SOUZA, E. P. M. Ginástica geral: uma área do conhecimento da Educação Física. Tese (doutorado). Universidade de Campinas, Campinas, 1997.

VAINFAS, R. História das mentalidades e história cultural. In: C. F. Cardoso; R. Vainfas, (Orgs.)

Domínios da história: ensaios de teoria e metodologia. Rio de

Esse artigo foi apresentado no IV Seminário de Estudos e Pesquisas em Formação Profissional no Campo da Educação Física- NEPEF, realizado na UNESP/Bauru de 20 a 23 de novembro de 2008.

\author{
Endereço: \\ Juliana Frâncica Figueiredo \\ Rua Castro Alves, 3170 Santana \\ Araraquara SP Brasil \\ 14801-450 \\ Telefone: (16) 81247712 \\ e-mail: jufrancica@hotmail.com
}

Recebido em: 30 de setembro de 2008.

Aceito em: 1 de novembro de 2008.

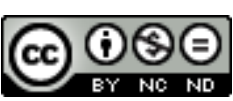

Motriz. Revista de Educação Física. UNESP, Rio Claro, SP, Brasil - eISSN: 1980-6574 - está licenciada sob Licenca Creative Commons 